\title{
,anu \\ COVID-19 Pandemic Impact on Substance Misuse: A Social Media Listening, Mixed Method Analysis
}

\author{
Davide Arillotta ${ }^{1} \mathbb{D}$, Amira Guirguis ${ }^{1,2} \mathbb{D}$, John Martin Corkery ${ }^{1} \mathbb{D}$, Norbert Scherbaum ${ }^{3, *}$ \\ and Fabrizio Schifano ${ }^{1}$ (D)
}

1 Psychopharmacology, Drug Misuse, and Novel Psychoactive Substances Research Unit, School of Life and Medical Sciences, University of Hertfordshire, Hatfield AL10 9AB, UK; davide.arillotta@yahoo.it (D.A.); a.guirguis2@herts.ac.uk (A.G.); j.corkery@herts.ac.uk (J.M.C.); F.Schifano@herts.ac.uk (F.S.)

2 Swansea University Medical School, Institute of Life Sciences 2, Swansea University, Singleton Park, Swansea SA2 8PP, UK

3 Department of Psychiatry and Psychotherapy, Medical Faculty, LVR-Hospital Essen, University of Duisburg-Essen, Virchowstraße 174, 45147 Essen, Germany

* Correspondence: Norbert.Scherbaum@lvr.de

Citation: Arillotta, D.; Guirguis, A.; Corkery, J.M.; Scherbaum, N.; Schifano, F. COVID-19 Pandemic Impact on Substance Misuse: A Social Media Listening, Mixed Method Analysis. Brain Sci. 2021, 11, 907. https://doi.org/10.3390/

brainsci11070907

Academic Editor: Michela Balconi

Received: 10 June 2021

Accepted: 5 July 2021

Published: 9 July 2021

Publisher's Note: MDPI stays neutral with regard to jurisdictional claims in published maps and institutional affiliations.

Copyright: (c) 2021 by the authors. Licensee MDPI, Basel, Switzerland. This article is an open access article distributed under the terms and conditions of the Creative Commons Attribution (CC BY) license (https:// creativecommons.org/licenses/by/ $4.0 /)$.

\begin{abstract}
The restrictive measures adopted during the COVID-19 pandemic modified some previously consolidated drug use patterns. A focus on social networks allowed drug users to discuss, share opinions and provide advice during a worldwide emergency context. In order to explore COVID-19-related implications on drug trends/behaviour and on most popular psychotropic substances debated, the focus here was on the constantly updated, very popular, Reddit social platform's posts and comments. A quantitative and qualitative analysis of $\mathrm{r}$ /Drugs and related subreddits, using a social media listening netnographic approach, was carried out. The post/comments analysed covered the time-frame December 2019-May 2020. Between December 2019 and May 2020, the number of whole $\mathrm{r}$ /Drugs subreddit members increased from 619,563 to 676,581 members, respectively, thus increasing by $9.2 \%$ by the end of the data collection. Both the top-level $r /$ Drugs subreddit and 92 related subreddits were quantitatively analysed, with posts/comments related to 12 drug categories. The drugs most frequently commented on included cannabinoids, psychedelics, opiates/opioids, alcohol, stimulants and prescribed medications. The qualitative analysis was carried out focussing on four subreddits, relating to some 1685 posts and 3263 comments. Four main themes of discussion (e.g., lockdown-associated immunity and drug intake issues; drug-related behaviour/after-quarantine plans' issues; lockdown-related psychopathological issues; and peer-topeer advice at the time of COVID-19) and four categories of Redditors (e.g., those continuing the use of drugs despite the pandemic; the "couch epidemiologists"; the conspirationists/pseudo-science influencers; and the recovery-focused users) were tentatively identified here. A mixed-methods, social network-based analysis provided a range of valuable information on Redditors' drug use/behaviour during the first phase of the COVID-19 pandemic. Further studies should be carried out focusing on other social networks as well as later phases of the pandemic.
\end{abstract}

Keywords: COVID-19; drug misuse; mixed methods; NPS; psychonauts; reddit

\section{Introduction}

Over the last 16 months, the SARS-CoV-2 contagion has spread worldwide, with a number of measures (e.g., social distancing and quarantine; [1]) having been taken as a result. In association with self-confinement at home, many users have increased their web access on a daily basis [2,3]. Users have turned to the internet for news, exchange of views and purchase of products, with increased levels of the associated risk of exposure to unverified sources of information [4-7]. Within the open web, in addition to common search engines, there are social networks/platforms. These include Twitter, Facebook, Telegram, Youtube, WhatsApp and Reddit [8-13]. 
Reddit is one of the most used English-language social media/platforms; in May 2020 it counted some 430 million active users and over 1.5 billion visits. Its usage is more prevalent among young (18-29 years old), white and Hispanic males, typically with some level of high school/college education. Most Redditors (Reddit users) are located in the United States $(49.8 \%)$, followed by the United Kingdom and Canada (respectively at 8.2 and 7.6\%), Australia (3.7\%) and Germany (3.1\%; [14-20]). Although the Reddit platform does not necessarily represent either the general, or the whole drug enthusiasts' population, it still appears as a large open web information source in terms of the number of posts and active users; variety of topics being discussed; and real-time discussion of trends. Hence, Reddit has been used for a range of research purposes, including both general psychiatry [21-28] and addiction/drug abuse [29-34]. Indeed, the social networks' web monitoring approach has been suggested to be helpful to better understand some clinical and psychopharmacological issues related to a range of novel psychoactive substances (NPS) [35]. This approach has been recently referred to as "social media listening" [36,37], with the resulting findings providing insight into how people discuss their condition online. This research approach is, however, being combined with qualitative research for added rigour and confirmation of relevance of the related findings, i.e., triangulation [37]. Over the years, netnography, a qualitative, interpretative research methodology that adapts traditional ethnographic techniques to the study of online (e.g., social media; web) data [38] has increasingly been used as a strictly observational, unobtrusive approach in a range of health research fields, including pro-anorexia [39] and diabetes mellitus online peer support [40] communities. Overall, web monitoring activities may well help in identifying a wide range of emerging/novel/previously undetected NPS [41-44]. A particular type of active user identified from the various virtual platforms are the e-psychonauts [45]. Their interest is addressed to the entire world of misusing substances, ranging from the classic ones to emerging psychoactive substances (EPS) [45-48]. The knowledge levels relating to the ever-growing number of NPS/EPS, motivations for use, sought-after psychoactive effects, idiosyncratic combinations, medical/psychopathological risks and clinical treatment/management are limited [48-53]. It has been suggested [54] that the current pandemic is having an impact on the supply of substances of abuse and their consumption, with the overall social, economic and health consequences of the pandemic itself not yet foreseeable [55-57].

Aims

We aimed here at providing an overview of both the content/quality and quantity of posts/comments relating to the psychotropic substances debate detectable from the Reddit platform during the early phase of the SARS-Cov-2 pandemic.

\section{Materials and Methods}

A quantitative and qualitative analysis of Reddit subreddits was conducted from December 2019 to May 2020. In order to investigate drug use issues among e-psychonauts, other Reddit users and the related possible COVID-19 pandemic impact, a mixed-methods (MM) strategy was adopted. With this approach, a range of qualitative and quantitative data are analysed in parallel to provide a better understanding of a specific issue [58-60]. More specifically, the quantitative component was here the result of the manual screening of Reddit posts/threads, whilst for the qualitative analysis a netnographic [38-61] approach was adopted. In this study, original posts and comments were included. In Reddit, "post" means the first content shared by a user (e.g., questions, thoughts, tips, experiences, pictures) and "comment" defines any eventual reply to this specific post. Data were collected from both the Reddit website and the r/Drugs' related subreddits; conversely, the r/covid19stack and r/Opioid_RCs subreddits were located from dedicated links [62-67]. More precisely, D.A. carried out the initial posts/comments' extraction activity; the range of free texts identified were screened and their proper, initial coding/categorization was drafted by D.A., a psychiatrist with quantitative/qualitative research experience assessing 
web-based NPS drug discussions. The findings and categorizations were then independently reviewed by F.S., a senior academic with proper teaching and research experience on quantitative/qualitative recreational/NPS drug research, in order to achieve an agreement to be presented to the whole researchers' group for both resolving possible disagreements and final approval of the quantitative analysis.

The quantitative search, relating to the $r$ /Drugs Reddit component and its related subreddits [66], was performed by inserting specific keywords into the search bar of each subreddit. This process included two phases. In the first phase, the latest/trendiest topics were explored, in order to obtain the keywords that were eventually used to refine further searches. The keywords first used here included "COVID", "coronavirus", "corona", "quarantine", "pandemic" and "lockdown". In the second phase, the titles/contents of the discussions were explored, whilst analysing the presence of the above mentioned COVID19-related keywords in all the r/Drugs subreddits. The threads adopting the "New" posts order criteria were screened here to facilitate optimal temporal discrimination. The Reddit new/trendy topics can be explored by considering the ranking functions (e.g., Hot, New, Top, Rising). This option allowed the exclusion of those posts/comments that were clearly antecedent to the beginning of the pandemic. Irrelevant/not applicable posts (e.g., where the term "corona" referred to a brand of an alcoholic drink) were excluded. To facilitate the manual keyword search, an Application Programming Interface (API), developed by Reddit users and hosted in a distinct website [68] (GitHub, 2020), was used. The search was repeated several times, a thousand to a thousand items at a time, and, hence, the 1000 item limit imposed by the native Reddit API [67] was bypassed (see Table S1).

\subsection{Qualitative Analysis}

The qualitative component of the research was carried out employing the netnographic approach. The qualitative analysis of both the whole $\mathrm{r} /$ Drugs subreddit and some related, most popular subreddits ( $r$ /HPPD; $r$ /StackAdvice; $r$ /Supplements) was conducted (see details in Table 1 and Table S2). The themes of these subreddits revolved around (a) general issues related to the range of available psychotropics; (b) the specific psychopathological consequences of drug intake; (c) the range of remedies considered by Reddit users in coping with untoward consequences of drug intake; and (d) peer-to-peer advice and social media sharing issues. Free texts (e.g., posts/comments) containing the selected keywords were examined; some representative quotes were then identified and grouped in the "main themes" Results section. A similar procedure was carried out to identify and group the different "types of users". In line with previous suggestions [69,70], the posts were selected whilst applying different and multiple sampling strategies. More precisely, the Palinkas et al. [7] theoretical sampling criteria were considered here to group the different types of users, whilst multistage (e.g., opportunistic or emergent) sampling criteria were considered to identify the main themes. The iterative process made it possible to refine and classify the posts/comments as representative for putative categories, until their screening was completed. The groups' classification was carried out taking into account the contents' variety of COVID-19 keyword-related posts using an inductive approach (e.g., generation of new theory emerging from the data; $[71,72])$.

Table 1. Included subreddits in qualitative analysis.

\begin{tabular}{|c|c|c|c|c|c|c|c|}
\hline Subreddits & $\begin{array}{c}\text { COVID } \\
\text { Posts/Comments }\end{array}$ & $\begin{array}{c}\text { Coronavirus } \\
\text { Posts/Comments }\end{array}$ & $\begin{array}{c}\text { Corona } \\
\text { Posts/Comments }\end{array}$ & $\begin{array}{c}\text { Quarantine } \\
\text { Posts/Comments }\end{array}$ & $\begin{array}{c}\text { Pandemic } \\
\text { Posts/Comments }\end{array}$ & $\begin{array}{c}\text { Lockdown } \\
\text { Posts/Comments }\end{array}$ & $\begin{array}{c}\text { Total } \\
\text { Posts/Comments }\end{array}$ \\
\hline r/Drugs & $158 / 538$ & $227 / 449$ & $210 / 402$ & $556 / 645$ & $127 / 195$ & $148 / 239$ & $1426 / 2468$ \\
\hline r/HPPD & $8 / 7$ & $5 / 16$ & $6 / 9$ & $11 / 15$ & $6 / 4$ & $3 / 14$ & $39 / 65$ \\
\hline r/StackAdvice & $16 / 31$ & $6 / 10$ & $3 / 10$ & $2 / 12$ & $4 / 12$ & $1 / 5$ & $32 / 80$ \\
\hline r/Supplements & $81 / 323$ & $54 / 187$ & $17 / 61$ & $16 / 32$ & $16 / 37$ & $4 / 10$ & $188 / 650$ \\
\hline Posts/comments & $263 / 899$ & $292 / 662$ & $236 / 482$ & $585 / 704$ & $153 / 248$ & $156 / 268$ & $1685 / 3263$ \\
\hline
\end{tabular}




\subsection{Data Collection and Privacy Disclaimer}

The current overall screening focussed on Redditors' COVID-19-related activities running from 01 December 2019 to 31 May 2020, in order to include the first six months of the COVID-19 outbreak [73]. The precise number of members made available by Reddit related only to the date in which the social platform was being accessed; conversely, no historical data of members' figures were made available from the Reddit platform. Hence, to better assess the possible levels of numerical fluctuations relating to both selected subreddits' members and posts/comments, the quantitative analysis was carried on the 11th day of each month, using 11th March 2020 as a time-point reference, with this date having been the date on which the WHO declared COVID-19 to be a pandemic ([74]; see Table S1).

Each subreddit content was freely accessible on the open web. In line with previous studies [27], full anonymity was guaranteed and no usernames or references to the Redditors were collected, used or analysed. The raw data were imported into Word and Microsoft Excel spreadsheets. Furthermore, according to the unobtrusive and naturalistic methods of conducting netnographic studies [48-61], no posts or other contributions to private/public forum discussions were made.

\subsection{Ethics}

The study was carried out within the framework of the University of Hertfordshire Ethics' Committee (code: aLMS/SF/UH/02951(2) approval).

\section{Results}

\subsection{Number of Subreddits and Their Classification}

On 11 December 2019 and 11 May 2020, 619,563 and 676,581 members were counted on the whole r/Drugs subreddit, respectively, with a $9.2 \%$ overall increase overtime.

\subsection{Included and Excluded Subreddits}

Some 217 subreddits related to $r$ /Drugs [66] were identified. However, some 127 subreddits, including Pics \& Videos, Music, Youtube, Festivals, Misc, Regions/Languages, Memes, 18+ \& NSFW were excluded from the analysis because they were deemed not relevant. Most typically, in fact, these subreddits focussed on a range of issues including pornography, sexmate searches, pictures, videos, memes and music festivals. Quantitative data regarding the remaining 90 subreddits were collected. Two further subreddits, albeit not explicitly listed within the macro r/Drugs subreddit itself but considered here as relevant (r/Opioid_RCs; r/covid19stack), were added, taking the total to 92 subreddits being analysed.

\subsection{Clinical and Pharmacological Subreddits' Classification}

Given the large variety of drug issues being discussed in these subreddits, and in line with previous clinical pharmacological classification of recreational drugs/NPS/EPS [75], the above subreddits were grouped into 12 categories (see Table S3). Moreover, it was identified that 20 subreddits focussed on "psychedelics" (PS); 13 on "cannabinoids (CA)"; 10 on "GABAergics, gabapentinoids and various psychotropic medications (GM)"; 9 on "cognitive enhancers/image- and performance-enhancing drugs (IPEDs)/supplements (CS)"; 9 on "opioids (OP)"; 5 on "generic subreddits and drug-induced disorders (GD)"; 5 on "dissociatives (DI)"; 5 on "beverages/brews and infusions (BI)"; 5 on "alcohol and cigarettes (AC)"; 4 on "stimulants (ST)"; 3 on "research chemicals (RC)"; 2 on "entactogens $(\mathrm{EN})$ "; and 2 on "other substances (OS)" subreddits. Within the "Addiction/Recovery", "Harm Reduction" and "Discussion" subreddits, those with less than 100,000 entries were excluded from the quantitative analysis (see Table S4) because they were considered anecdotal/less representative.

Those drug categories that, in terms of posts' numbers, received more attention included the following: CA, PS, OP, AC, ST; and, in terms of comments, the categories in- 
cluded the following: CA, OP, CS, PS, GM. Overall, the largest numbers of posts/comments were identified from the "Drugs \& Activities" group.

Among the "Drugs A-Z" group, the largest number $(n=1,553,229)$ of Redditors related here to $r /$ trees. Considering an arbitrary cut-off of $100 \mathrm{~K}$ members, in terms of popularity it was followed in decreasing order by $r$ /LSD, $r$ /Nootropics, $r$ /shrooms, $r$ /DMT and $\mathrm{r}$ /Supplements. Within the "Discussion" group, the largest number of members belonged to $\mathrm{r} /$ Psychonaut $(\mathrm{n}=282,864)$, followed, with about/more than $100 \mathrm{~K}$ members, by $\mathrm{r} /$ vaporents and $\mathrm{r} /$ DrugNerds. Within the above-mentioned timeframe, the largest members' number (e.g., in excess of $100 \%$ ) increase was observed in the following subreddits: r/covid19stack, r/Opioid_RCs, r/mescaline and r/MephHeads.

\subsection{Supplements and Remedies}

Some 87 supplements (e.g., vitamins, minerals, herb/botanical/plant extracts, aminoacids, traditional medicine products) and 7 remaining non-chemical remedies were identified as modalities to boost the immune system (See Table 2). The supplements' and remedies' list was extracted from three subreddits included in the "Therapeutic use" section of "cognitive enhancers/PIEDS" group (r/covid19stack, r/StackAdvice and r/Supplements) (See Table S3).

Table 2. Supplements and remedies in alphabetical order discussed in $r /$ covid19stack, $\mathrm{r} /$ Supplements and $\mathrm{r} /$ StackAdvice.

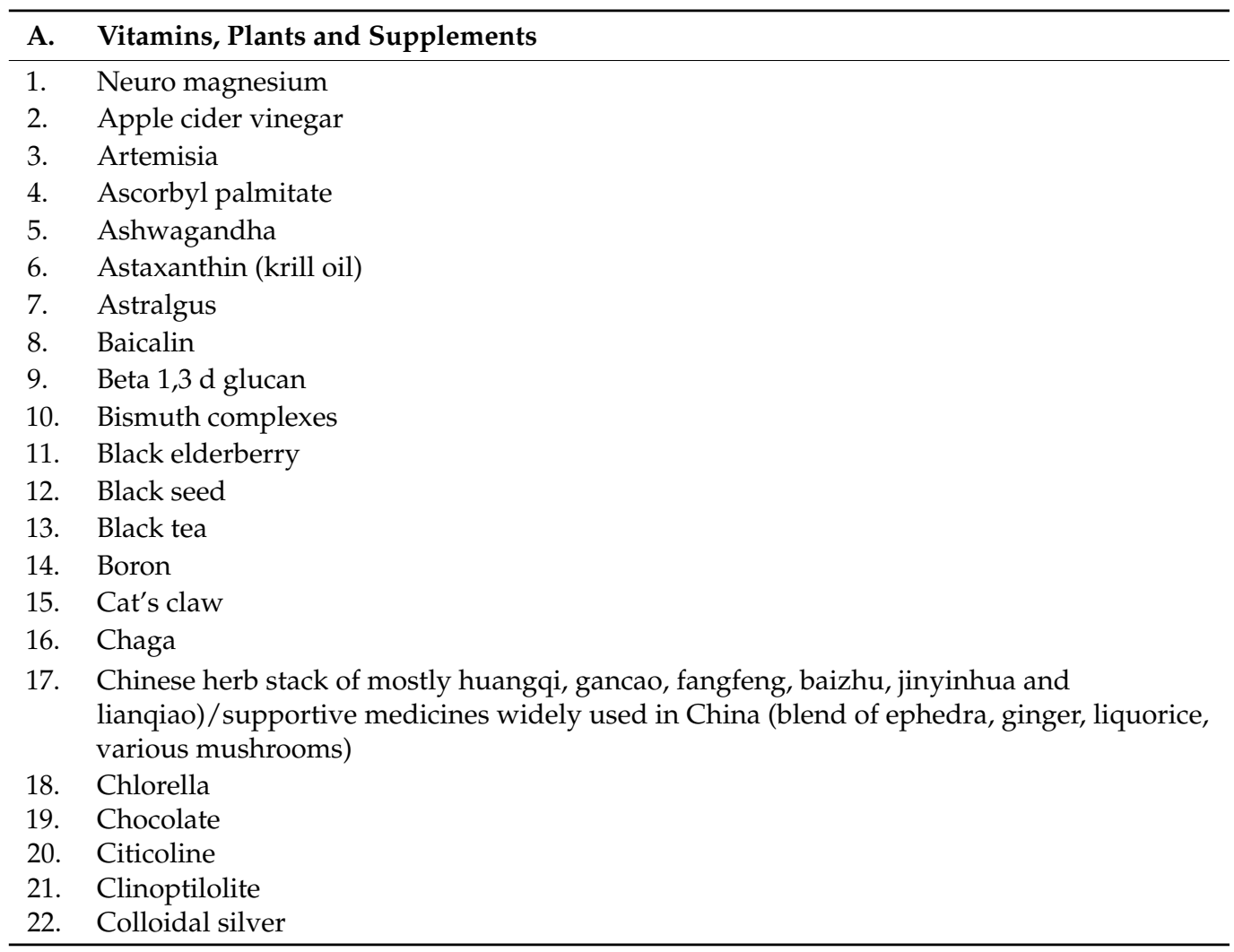


Table 2. Cont.

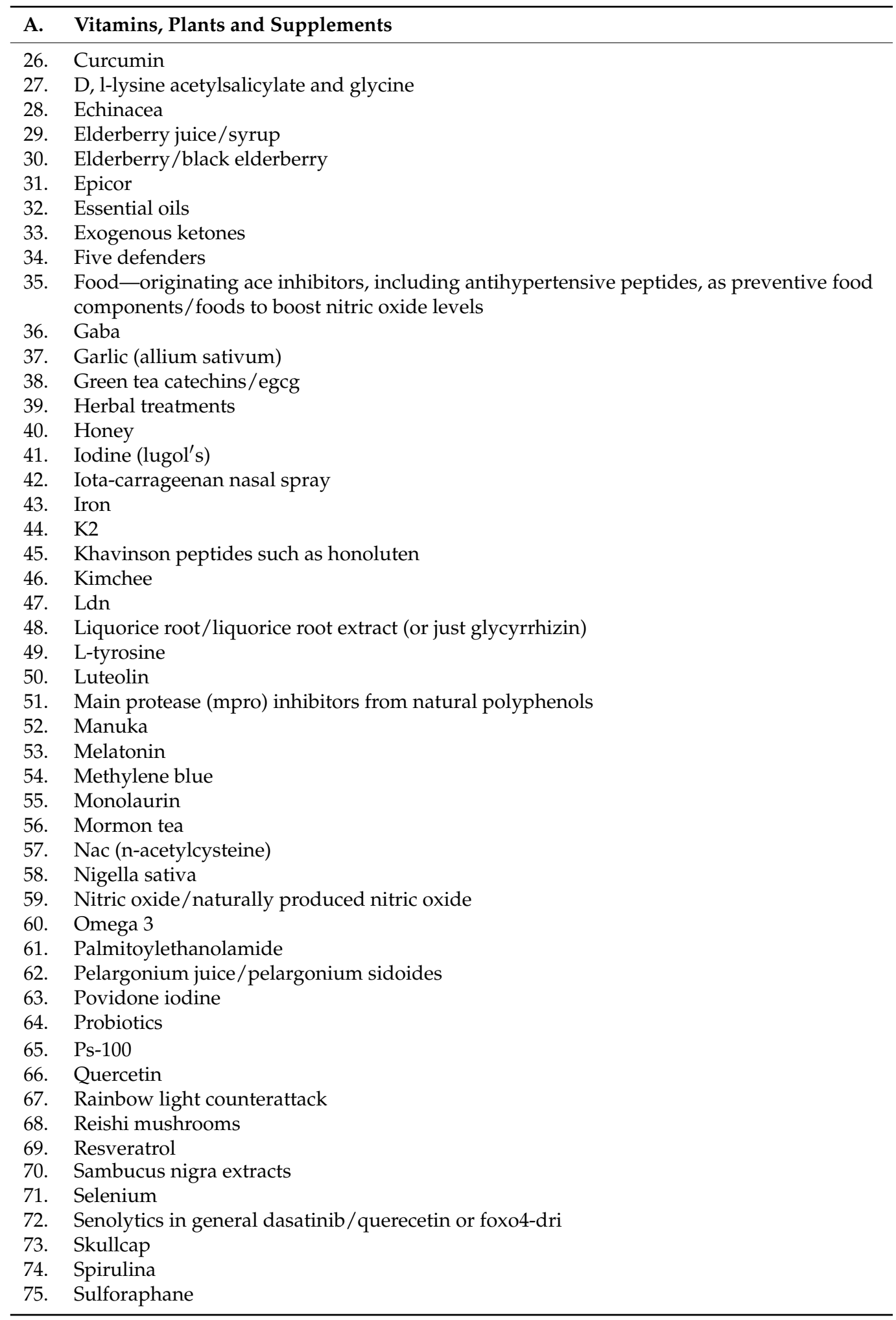


Table 2. Cont.
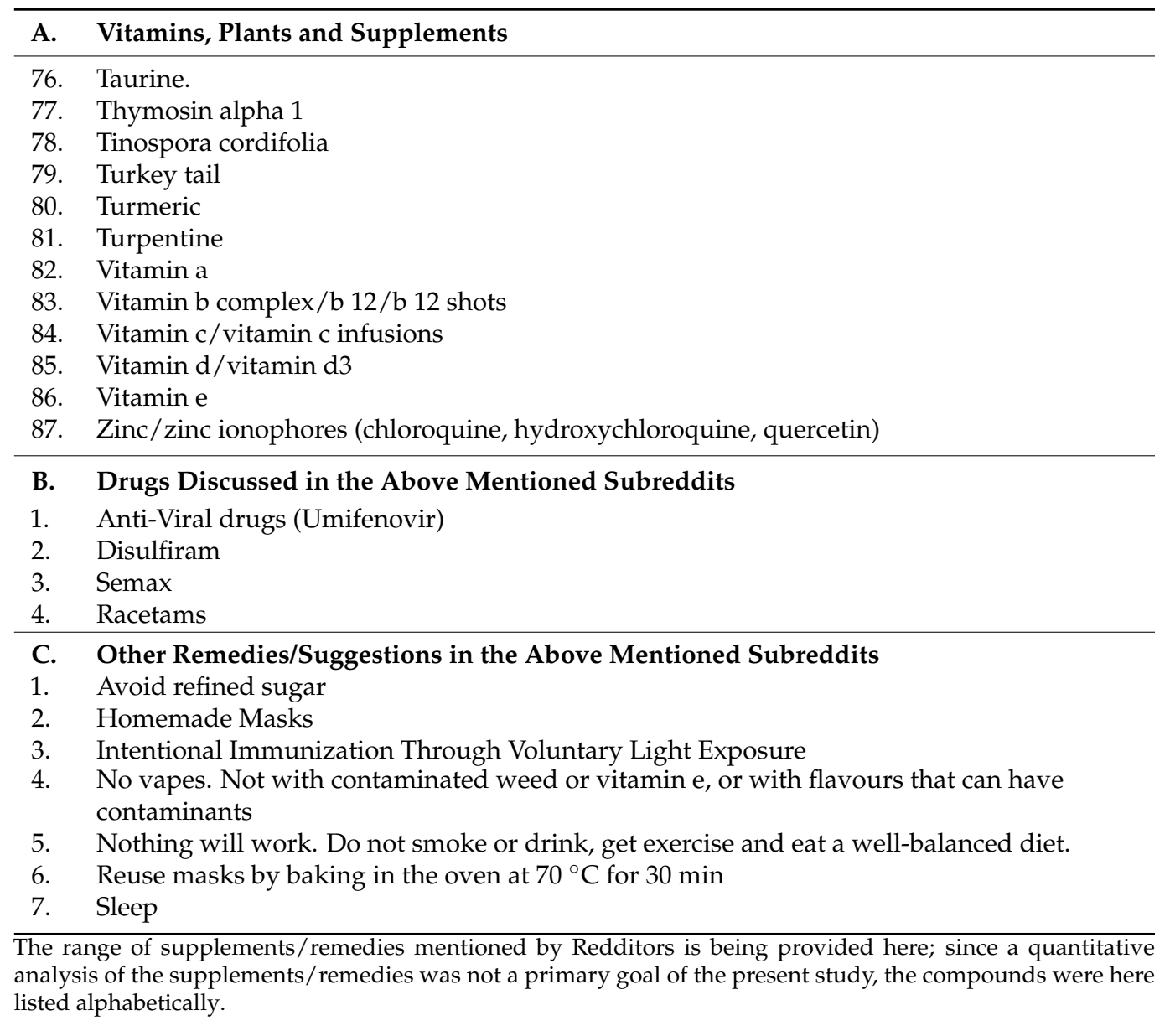

According to the current keyword criteria search, the first COVID-19-related posts/comments were dated 22 January 2020 (r/steroids) and 23 January 2020 (r/ketamine; r/researchchemicals) (See Table S1); users commented about the related health/sanitizing concerns (e.g., ( ... ) So a lot of street $\mathrm{K}$ is coming from China and I'd say its safe to say sanitation is probably not a criminal operation's main priority ( ... ) So, I wonder if its poasible to get contaiminated drugs from the area? ( . . ) -Yeah I heard about the coronavirus. Scary shit! ( . . )).

For further details on members and individual keyword data on posts/comments, see Tables S1-S3.

\subsection{Main Themes Being Discussed}

Regarding cannabinoids, the focus was most typically on cultivation issues, whilst for psychedelics, cognitive enhancers and GABAergics/prescribed/over the counter (OTC) medications, the discussion revolved around the large range of related molecules. Conversely, NPS/EPS were typically listed in the "research chemicals" group, and, in particular, $\mathrm{r}$ /researchchemicals and r/Opioid_RCs. Finally, addiction recovery issues were identified from virtually all the analysed drug groups (for further details, see Table S1). Most typically, subredditors discussed a large range of themes, but four main themes were tentatively identified (see Table 2 and Table S2).

A total of four subreddits (relating to a total of 1685 posts and 3263 comments, as shown in Table 2) were screened for the qualitative analysis. From the whole list (see Table S2), they were selected according to the following criteria: $r$ /Drugs, the main subreddit, since focussing on cross-cutting themes and general discussions; $r / H P P D$, the only r/Drugs related subreddit focussing on drug-induced disorders (Reddit, $2020 \mathrm{~g}$ ); $\mathrm{r}$ /StackAdvice, dealing with the best drug stacking advice; $r$ /Supplements, debating the different supplements and remedies to use to cope with possible drug/COVID-19- 
related untoward consequences. Due to the large volume of raw data generated, irrelevant posts/comments were excluded and manually removed from the data set. Following the removal of post/comments, the most relevant posts/comments $(n=190)$ were listed in Table S2: 69 on main theme one; 73 on main theme two; 16 on main theme three and 21 on main theme four. A brief summary of the issues debated within the four main themes is provided here (see also Table 3).

Table 3. Main themes summary.

Main Theme 1. The Lockdown-Associated: Immunity, Psychotropic(s) of Choice and Drug Dosage/Intake Issues.

- $\quad$ Sub-theme 1. Drug use and impact on immunity levels.

- Sub-theme 2. Looking for the optimal recreational/prescribing drugs, alone or in combination, to cope with the pandemic.

- $\quad$ Sub-theme 3. Drug dosage adjustment and intake modalities' issues.

Main Theme 2. Life at the time of COVID-19, drug dealing, drug-related behaviour and post-quarantine plans' issues.

- Sub-theme 4. Drug supplying and "customer care" issues.

- Sub-theme 5. Drug-related behavioural issues.

- $\quad$ Sub-theme 6. Post-quarantine plans.

Main Theme 3. Lockdown-related psychopathological issues.

Main Theme 4. Peer-to-peer advice at the time of COVID-19.

3.5.1. Main Theme 1. The Lockdown-Associated: Immunity; Psychotropic(s) of Choice; and Drug Dosage/Intake Issues

Sub-theme 1. Drug use and impact on immunity levels. Table S2, page 1 . The need to boost the immune response with specific drugs was a hot topic.

- (. . ) Substances that boost immune response? (.. ) Im curious in both recreational and non recreational ones. ( ... Edit: please provide evidence for claims while making them .......

- $\quad(\ldots)$ i read kratom actually boosts your immune system. I could swear thats why I never get sick lol-Maybe don't do MDMA or other drugs that mess with your immune system);

- $\quad(.$.$) Hey, sorry is this is a dumb question, but: is there anything I can do to molly to$ make sure that COVID isn't on it? Should I attempt to wash the pill, or?);

- $\quad(.$.$) A cocaine only diet provides all the nutrients you need. Food is just a burden$ for the weak).

- $\quad$ (. . ) So cocaine doesn't cure covid-19?; I doubt that vaping cannabis will affect your immune system very much.

- (.. ) Anyone know if suboxone effects the immune system much? If the answer is yes don't tell me, I get severe health anxiety. e.g., What if you have AD/HD and use amphetamines daily as treatment? Will this impact my immune system if I stick to the dosages I've been instructed to use by my physician?; e.g., Tripping with Schizophrenia (opinions?).

- Sub-theme 2. Looking for the optimal recreational/prescribing drugs, alone or in combination, to cope with the pandemic. Table S2, pages 1-3.

- $\quad(.$.$) I am bored in quarantine and I am out of weed and benzo as my dealer got$ coronavirus and stopped delivering. I am looking for another way to get high-DMT, Shrooms, Ketamine, Edibles/Weed, Opioids, Benzos, Cocaine are all good indoor drugs.-Cant smoke in my house when parents are in, need a non smelly drug.

- (.. What's in your doomsday stash? What would you still like to add before lockdown happens (assuming we end up like Italy)? What kind of activities do you like to do while high to pass the time? Here's a rundown of what I've got: Codeine $30 \mathrm{mg}$; lots of it. Weed in various forms from the dispensary ( 3 vape carts, 4 bags of 
gummies, $2 \mathrm{~g}$ of flower, 2 strains I grew myself, etc). CBD flower \& isolate. Kratom; lots of it. Benzedrex inhalers $\times 2$. Caffeine tablets, $200 \mathrm{mg}$. Xanax, $0.5 \mathrm{mg}$. Norco (as of yesterday, thanks dentist!), $7.5 \mathrm{mg} \times 20$ tabs. Fioricet $\times$ about 20 tablets. Coca powder \& tea bags $\times 100 \mathrm{~g}$ powder, 5 teabags. Various random drugs I don't take (methocarbomol, alcohol, guanfacine, klonopin, phentermine).-I work from home right now, so cocaine is next to my workstation-Forced to detox off amphetamine because it doesnt get made in my country and every country in eu is on lockdown ... Maybe i'll turn into alcohol or weed for the time being who knows.)

- $\quad$ ( . . ) (e.g., a bit of weed + a sniff of midma + a bit of acid all while coming up on some that juicy rona fever 3 stay safe but if you hit that rona make sure to stay hydrated 69 edit: ok i'm not funny this is just a joke about covid-19 fever: (; Phenibut + caffeine + weed + xanax is fucking awesome

- (.. - - Anybody else ever make "potions"? Examples would be ground klonopin in Kratom tea, maybe a splash of vodka or something. Wine, vodka, beer, vyvanse all mixed together. Etc, etc. Quarantine has clearly driven me crazy).

Sub-theme 3. Drug dosage adjustment and intake modalities' issues. Table S2, pages 3,4 .

- (. . ) Will i feel anything on $95 \mathrm{mg}$ od codeine? ... so i have A couple of codeine phosphas + sulfgogaiacolum shit will this get me high? I'm just so desperate cuz covid makes everything so hard to get-I can no longer workout without getting high.

- (. . ) However due to the Covid-19 lockdown, I've had to workout at home. Being at home has led to me getting high on the reg, and before working out cause it feels AMAZING.

- $\quad$ ( . . ) I don't feel the need to take the Tramadol generally, but to workout I feel like I need it).

- (.. ) ADHD medication ... Does anyone know if doctors are allowed to mail the prescription in the mail so I can take it to a pharmacy here?

- $\quad(.$.$) Quit Heroin due to quarantine. Don't applaud, I'm still using all kinds of other$ shit.-Trams anyone? I have no access to my other vices except trams.

- (.. ) Quitting Smoking (tobacco) During an Impossibly Stressful Time I've been trying to keep myself distracted, but I honestly wasn't prepared for the intensity to which my depression has worsened as a result of this.-Nicotine withdrawals weren't too bad).

- $\quad(.$.$) Too anxious to smoke up ... Concentrates and herb vaping should be easier on$ your lungs just empty the joints if you have a vape. Also oral and sublingual methods, edibles/tincture/distillate.

3.5.2. Main Theme 2. Life at the Time of COVID-19; Drug Dealing; Drug-Related Behaviour; and Post-Quarantine Plans' Issues

Sub-theme 4. Drug supplying and "customer care" issues. Table S2, pages 4-5.

- $\quad$ (. . ) My dealer just dropped off a whole care package for me, lsd, shrooms, shatter and dmt ... The man knows what I like ... Tells me he knows that times are tough, that being stuck at home sucks and he hopes this helps and didnt ask for a penny.

- (.. ) They've gotten more expensive where I live-Where I live, supply and demand have both gone up. Shit's popping off more than ever but they have no problems keeping it stocked

- $\quad(.$.$) I think the biggest impact will be on supply chain. Will dealers stop selling?$ Definitely not, that'd mean giving up a source of income in a time of high unemployment. The supply chain thus spreads the virus. Lockdowns and quarantines will not deter addicts.

Sub-theme 5. Drug-related behavioural issues. Table S2, pages 5-8.

- (. . ) I'm gonna use this quarantine to get sober and hopefully get back to just socially drinking/using-Please tell me I'm not the only one this desperate 
- (..) I scraped my grinder with a pocket knife for an hour and rolled a spliff that tasted like plastic. Due to my low tolerance it kinda worked though. These quarantine times got me doing desperate shit;).

- (.. ) I finally wrote a report on DMT ... I was stricken with worry about their fate amidst the COVID-19 pandemic. I began to project how I would feel if they were to pass from it, to empathize with that potential future trauma.-Worst time to trip

- (...) Got crazy drunk last night, took a heroic dose of acid, throwing up on acid is rough, throwing up thinking you have corona virus is the absolute worse thing ever. Still tripping, life is definitely weird $\mathrm{rn}$ ).

- ( . . ) I am not into conspiracies, but I can't help thinking about e.g., DMT being illegal around the world.-Think about your National Health Service please

- (..) You might think you know what you can handle but right now is not the time to risk it. This is for your benefit too-Nice haha, yeah I think this quarantine has affected everyone for better or for worse).

Sub-theme 6. Post-quarantine plans. Table S2, page 8.

- $\quad$ ( . . . ) How to Structure Multiple-Drug Trip (Weed, LSD, Shrooms, DMT, E)

- (.. ) Me and a couple of friends are looking to go on an Airbnb trip post-quarantine (thinking of 5 days, not sure though) and we're wondering how exactly we should structure our time).

3.5.3. Main Theme 3. Lockdown-Related Psychopathological Issues

- (... ) a week after I got off the Methadone, the whole Covid-19 crap and other stuff in my life whacked me with hella stress, anxiety, and palpitations. Soooo I'm back on the dope:/just trying to not lose it completely. What I need is to find a psychiatrist and counselor-I have all the same things in my mind every day actually. I want to take some drugs but trying prevent me from this. Also i'm in mental struggle with myself that borders with the depression.

- (... ) HPPD keeps giving me a shit ton of anxiety, advice? (... ) Now that i'm in quarantine i can't stop thinking about it). Table S2, Pages 10-11

3.5.4. Main Theme 4. Peer-to-Peer Advice at the Time of COVID-19

- (...) Before you take a heroic dose or try a new drug/batch ... Please make certain what you are doing is safe. Hospitals are more overloaded than usual due to COVID19.

- $\quad(.$. ) Meditate for Peace, Health and Happiness. Develop Monk-Like Discipline and Peace of Mind During These Anxious and Uncertain Times. Wishing everyone all the love, joy and blessings

- (... ) Day \#1-Join me in the Dopamine Fasting Challenge during the COVID Self Isolation!). Table S2, Pages 9-11

\subsection{Categories/Types of Users}

In analysing all of the posts and comments, four types of users were tentatively identified. Indeed, the COVID-19 pandemic seemed to have impacted the drug supply chain, drug choice and users' behavioural changes in various ways. One could argue that there are differences in reacting to the pandemic due to individual characteristics, place of living and personality traits. Those topics most typically debated revolved around COVID-19 health-related concerns, reliable psychological/psychiatric indicators of distress, loneliness, the desire to obtain an altered state of mind to better cope with boredom and troubles in accessing proper medical prescriptions. Some examples are provided here, with further clinical vignettes available in Table 4 . 
Table 4. Categories/Types of users.

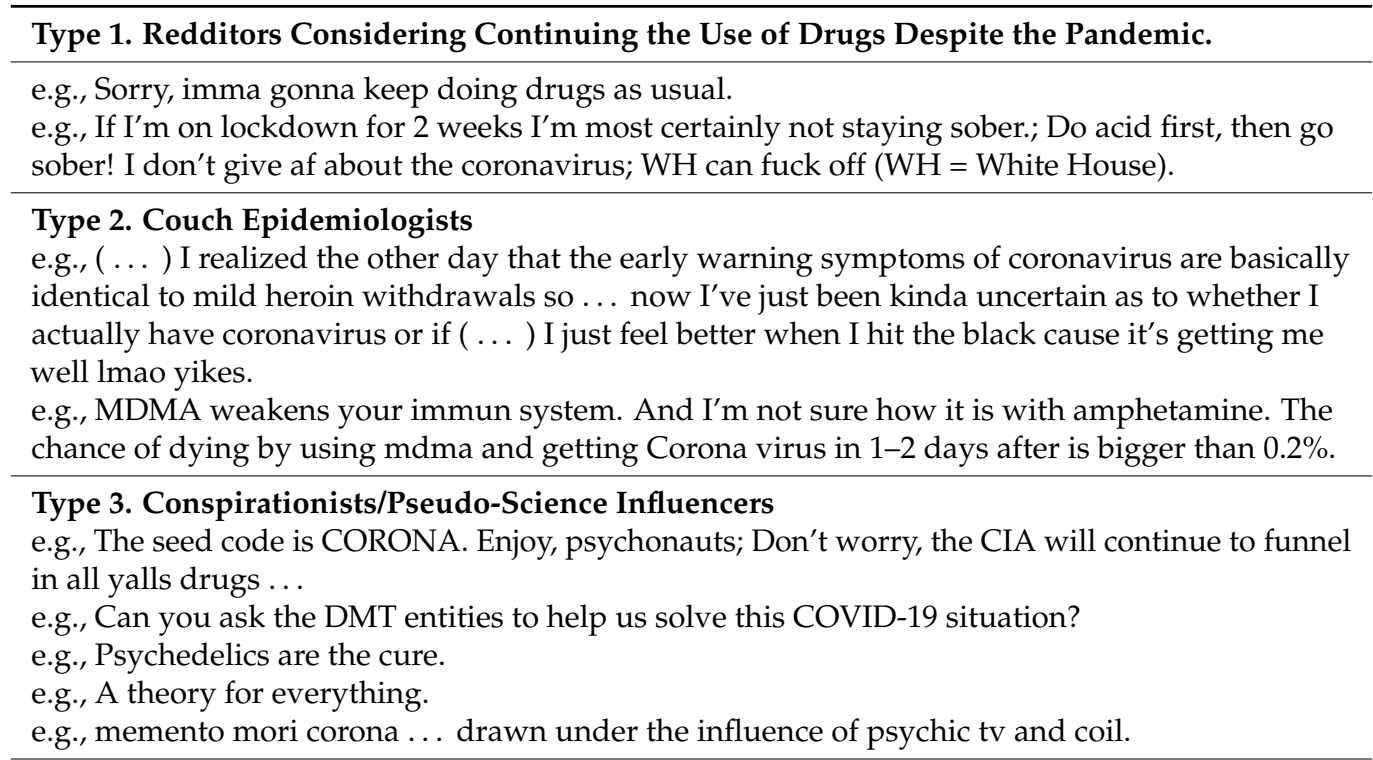

\section{Type 4. Recovery-Focused Users}

e.g., Despite lockdown, and other posts on here, you DONT have to relapse. This time can be used for recovery instead .......

e.g., Guys! Being sober can be really nice, too ...

e.g., Ok dad, I'll stop the molly.

3.6.1. Type 1. Redditors Considering Continuing the Use of Drugs Despite the Pandemic (... ) Sorry, imma gonna keep doing drugs as usual.

\subsubsection{Type 2. Couch Epidemiologists}

(... ) I realized the other day that the early warning symptoms of coronavirus are basically identical to mild heroin withdrawals so ... now I've just been kinda uncertain as to whether I actually have coronavirus or if ( . . ) I just feel better when I hit the black cause it's getting me well lmao yikes.

MDMA weakens your immun system. And I'm not sure how it is with amphetamine. The chance of dying by using mdma and getting Corona virus in 1-2 days after is bigger than $0.2 \%$.

\subsubsection{Type 3. Conspirationists/Pseudo-Science Influencers}

(... ) The seed code is CORONA. Enjoy, psychonauts; Don't worry, the CIA will continue to funnel in all yalls drugs ......

(... ) Can you ask the DMT entities to help us solve this COVID-19 situation?; Psychedelics are the cure.

\subsubsection{Type 4. Recovery-Focused Users}

(... ) Despite lockdown, and other posts on here, you DONT have to relapse. This time can be used for recovery instead ... . . . e.g., Guys! Being sober can be really nice, too ......

( . . ) Ok dad, I'll stop the molly.

\section{Discussion}

The present research has been conducted on a major and very popular social network, covering a time-period of six months, aiming at exploring the relationship between COVID19 and substance misuse through a social media listening approach. In order to outline a comprehensive picture of the phenomenon, a large number of posts/comments, using a netnographic approach, were analysed here. At present, although the pandemic has been 
going on for several months, the attention of both the scientific literature and the media has mostly been directed to its medical/virological aspects. Conversely, only a few efforts have been made to clarify the impact of the COVID-19-related lockdown on both mental health and patterns/styles of recreational drug intake. For this reason, the current research focus was on the first six months of the pandemic, months that have been characterized by the strongest levels of self-isolation. From this point of view, for some vulnerable individuals, the only possible travel at that time was a "trip", whilst being connected with peers through social media.

With the very best of our understanding, the current paper is likely to represent the first mixed-methods, large sample size, empirical investigation focussing on behavioural changes in drug intake during the first six months of the COVID-19 pandemic using a social media listening approach. Other studies have aimed at describing the trends in substance use during the current pandemic [43,44,76-81], without considering the need to carry out large-scale, social media mining, research activities [82-84]. Per definition, lockdown has been, and for some countries still is, characterised by both social confinement and human isolation. In parallel, the use of both the web and social media has increased considerably to maintain human contacts, hence the importance of assessing the drug enthusiasts' online entries [54]. As previously highlighted, the online and offline worlds influence each other $[85,86]$, although the directionality and the extent of these phenomena are not always clear. For social listening, Reddit was chosen here as the platform to be investigated. Although the Reddit platform does not provide precise data relating to its total members during the period December 2019-May 2020, anecdotal data have suggested that Reddit, as a social platform, recorded a spike in engagement during the pandemic [87]. The interest in social media during the pandemic has been explored by recent remaining studies as well [88].

Different from other social networks such as Facebook, Twitter, etc., Reddit promotes anonymity, with some Redditors describing themselves in different fantasy ways (e.g., "friendly faces" in r/Drugs; "tryptonaut" in r/tryptonaut; "bartards" in r/benzodiazepines; "dextronauts" in r/dxm; "opiate enthusiasts" in r/opiates; "ents" in r/trees; "salvia people" in $r$ /Salvia, "Vaporists" in $r$ /vaporents, etc.). Indeed, these nicknames may emphasise the importance of the sense of belonging to a sub-culture, different from the remaining sub-tribes and, indeed, from the "druggies" as well.

Overall, Redditors showed a strong tendency to share with their peers a range of materials (e.g., pictures, links, trip reports), to facilitate mutual help activities ("sharing for caring, sharing for drugging"). Users' posts and comments focussed on a range of COVID-19-related issues; health and sanitising issues were frequently mentioned, including the quality/possible contamination of drug products and the risks of health consequences $[80,89]$ in those with underlying chronic medical conditions. Many users asked for some advice about the possible of use of specific supplements to boost their immune system [90-94] and, indeed, the current pandemic stimulated the search for a range of psychotropics with only limited levels of potential harm on both the respiratory and the immune systems. In line with this, more attention was given to oral, as opposed to inhaled, modes of intake. Furthermore, there were a large number of posts related to both the indoor cultivation (e.g., of cannabis) and intake of edible products (see Table 2).

The recent literature has highlighted the dramatic impact of COVID-19 on mental health [95-98]. In line with this, various posts related to a range of possible concerns (e.g., anxiety, depressive, psychotic, hypochondriac, obsessive-compulsive), although this was not necessarily associated with a modification of Redditors' drug consumption patterns. A special focus of the debate was here on the Hallucinogen Persisting Perception Disorder (HPPD) $[99,100]$, with users asking for remedies to treat the problem, due to the impossibility of visiting clinicians/specialists.

COVID-19 affected drug markets in various ways, with sudden changes in drug purity/potency, price and supply/availability levels [80,101,102]. These issues were hotly debated here, especially in some subreddit groups (e.g., r/Addiction; r/Recovery). Al- 
though no obvious drug exchange elements were reported here, likely because these activities are explicitly discouraged by Reddit moderators with a penalty consisting of being banned, characteristics of drug delivery activities were reported, with specific reference to some dealers' optimal "customer care" approach.

Overall, the quarantine regime seemed to have encouraged Redditors to develop a range of consumption coping strategies, including conservative (e.g., continuing with drug intake using stocks of purchased drugs); a switch to NPS, which can be bought online and delivered by the postman whilst avoiding legal issues; abandoning drug use and looking for new alternative activities (e.g., studying, doing physical exercise/workout) to be put in place to cope with the lack of psychoactive drugs. Interestingly, whilst some users tried to minimise the risks related to the modified lifestyle scenario, others showed relative levels of carelessness, with several comments having been related here to a range of conspiracy theories, otherwise widely disseminated in social media [103,104].

Whilst all the drug categories attracted Redditors' attention, cannabis, alcohol, psychedelics, opioids and cognitive enhancers were the most popular drugs [105]. Due to their availability levels, alcohol and cannabis were often cited as replacement, "comfort", psychotropics. Conversely alcohol polydrug use [106], to obtain an intense dissociative/detachment from the current contingency, was noted as having increased during lockdown.

Although some users seemed to be cautious about using substances at home during the pandemic, for others (e.g., "psychonauts"; $[43,44,47,107,108]$ ), the confinement experience triggered the use of NPS and/or psychedelics to facilitate insight and mental exploration issues. Indeed, some $\mathrm{r} /$ DrugNerds and $\mathrm{r} /$ researchchemicals Redditors seemed to focus on a compulsive search for new molecules to be tried. The availability of such posts and comments may have contributed to both the spread of "infodemia" [109] and to the related risks associated with the intake of NPS presenting with only little, or none at all, clinical pharmacological knowledge [75,110-112].

Consistent with previous research [54,113], significant at home, lockdown-related levels of use of both prescribed and OTC sedative drugs during the COVID-19 pandemic were identified. One could speculate that this was carried out to obtain an ad hoc, cloudy/obtunded ("four walls' daze"; Yan et al., 2020), state of mind to best cope with both boredom and loneliness. In other cases, the switch to the psychotropics available at home, such as the prescribed/OTC medications, was carried out because of the lack of access to the preferred recreational drugs(s). On the other hand, many users complained that they were unable to renew their prescriptions, for the impossibility of going outside/visiting a doctor.

Whilst pre-COVID-19, web-based drug enthusiasts' categorisations had already been made available [81], an attempt at categorizing Redditors with respect to their approach to drug use at the time of COVID-19 is proposed. Although the importance of personality traits is, indeed, relevant in deriving categories of drug users, assessing the Redditors' personality dimensions was not the aim of the current study [114-119]. Specific personality issues could well have influenced the single subjects' drug use intake/related behaviour during the pandemic itself. Indeed, reference to specific temperament and character traits, including the four dimensions of temperament (e.g., novelty seeking, harm avoidance, reward dependence and persistence); and the three dimensions of character (e.g., selfdirectedness, cooperativeness and self-transcendence; [120-126]) could have been of help here in interpreting the range of different drug-related behaviour described. These behaviours included persisting in careless drug use, arguably suggesting low levels of harm avoidance; high novelty seeking levels, possibly characterising those attracted by NPS; high self-transcendence levels in those looking for NPS/novel psychedelics; antisocial personality traits in those allegedly refusing to wear a face mask whilst in others' presence [127]; with neuroticism, hypochondria and "coronaphobia" in those in need to be reassured whilst still using drugs [128-132]. Furthermore, the different attitudes described here could have been associated as well with the subject's environmental/social context, family/work background, age [48], attachment styles and cognitive biases [116,133,134]. 


\section{Limitations}

The current study presented with a few limitations. First, the current approach was adopted whilst considering both the empirical phenomenology model [135] and grounded theory principles [136,137], although one could argue the investigation was not fully in line with these approaches. Furthermore, the quantitative/qualitative posts/comments' assessment was carried out manually, whilst ad hoc software to analyse specific subreddits was used before [34,138-140]. Conversely, the manual searching approach likely enhanced the value of the entries' qualitative assessment here, fully in line with netnographic analysis principles $[35,141]$. On social media, people tend to speak freely and that by itself is an advantage, unlike other methods of obtaining data such as focus groups or interviews. On the other side, social data analysis may imply biases, methodological pitfalls and ethic boundaries [142]; for, e.g., it could be argued that Redditors represent an extremely varied population, potentially including a large plethora of users such as e-psychonauts, academics/researchers, curious people, trolls and trend influencers. Moreover, social media/Reddit users are only partially representative of people who use drugs in general; for, e.g., as recently highlighted, not all persons with drug-related problems have access to PCs/smartphones [143]. Finally, only the first few months of the COVID-19 pandemic were analysed here, and, at the time of writing, this pandemic is not over yet.

\section{Conclusions}

The current mixed-methods, qualitative and quantitative, focus on Reddit entries provided a range of valuable information relating to drug use at the time of COVID-19, thus confirming that social media analysis allows both trend and real-time data to be obtained. This approach is potentially useful for a wide range of researchers, clinicians and stakeholders, e.g., psychiatrists, psychologists, pharmacologists, sociologists, harm reduction projects. A tentative Redditors' categorisation has also been proposed. Personality traits/cognitive bias, attachment styles, health/psychiatric worries, medical access issues, living/consumption settings and pressure to expose contents/thoughts could probably explain the different detected reactions. The Reddit community seems to auto-regulate itself with harm reduction advice, but various drug users' trending patterns could worry clinicians and institutions. Further studies should be carried out by adding country-specific keywords, more subreddits/drug themes and focusing on other social networks as well. More studies should expand the potential of this approach in systematically exploring social networks in order to offer ideas for further investigations. Understanding the cultural, behavioural and psychological nuances/patterns related to the multi-faceted world of drug consumption, could help in designing new drug treatment/management and prevention strategies tailored to peculiar/new/changing contexts such as the COVID-19 pandemic.

Supplementary Materials: The following are available online at https:/ / www.mdpi.com/article/10.3 390/brainsci11070907/s1, Table S1: Selected subreddits' quantitative analysis: members, posts/comments by keywords, grouped by pharmacological classes (vertical) and according to redditor's classification (horizontal), Table S2: Main Themes, Table S3: Selected subreddits for quantitative analysis, Table S4: $\mathrm{r}$ /Drugs related subreddits (as grouped by redditors).

Author Contributions: D.A. and F.S. conceived the idea of this paper; data were extracted by D.A., whilst F.S. supervised all stages of the process and was consulted to resolve any possible issues. D.A. drafted the first version of the manuscript and revised it after contributions from J.M.C., A.G., N.S. and F.S. All authors have read and agreed to the published version of the manuscript.

Funding: This research did not receive any specific grant from funding agencies in the public, commercial, or not-for-profit sectors. We acknowledge support by the Open Access Publication Fund of the University of Duisburg-Essen.

Institutional Review Board Statement: The study was conducted according to the guidelines of the Declaration of Helsinki, and it was carried out within the framework of the University of Hertfordshire Ethics' Committee (code: aLMS/SF/UH/02951(2) approval). 
Informed Consent Statement: Data were mined from a publicly available social media platform (Reddit), without interacting with, intervening, or manipulating/changing the website's environments; no registration was required to read the threads/posts/comments online. Being common and ethically tenable in research activities using online forums/platforms, forum users were not informed about their posts being used for research purposes. We read MDPI's position on ethical publication issues.

Data Availability Statement: The sources from which the data presented in this study are derived are properly mentioned within the article and supplementary material.

Acknowledgments: This research did not receive any specific grant from funding agencies in the public, commercial, or not-for-profit sectors. We acknowledge support by the Open Access Publication Fund of the University of Duisburg-Essen. We thank Arianna Arillotta (student in artistic design for the enterprise in Albertina Academy of Fine Arts of Turin) for art graphics.

Conflicts of Interest: F.S. was a member of the UK Advisory Council on the Misuse of Drugs (ACMD; 2011-2019) and is currently a member of the EMA Advisory Board (Psychiatry). J.M.C. is a member of the ACMD's Novel Psychoactive Substances and Technical Committees. N.S. received honoraria for several activities (advisory boards, lectures, manuscripts) by the factories AbbVie, Camurus, Hexal, Janssen-Cilag, MSD, Medice, Mundipharma, Reckitt-Benckiser/Indivior, and Sanofi-Aventis; during the last three years he participated in clinical trials financed by the pharmaceutical industry. A.G., D.A.: nil to declare.

\section{References}

1. Advice for the Public on COVID-19-World Health Organization. Available online: https://www.who.int/emergencies/ diseases / novel-coronavirus-2019/advice-for-public (accessed on 6 June 2021).

2. Rathore, F.; Farooq, F. Information Overload and Infodemic in the COVID-19 Pandemic. J. Pak. Med. Assoc. 2020, 70, 162-165. [CrossRef] [PubMed]

3. Király, O.; Potenza, M.N.; Stein, D.J.; King, D.L.; Hodgins, D.C.; Saunders, J.B.; Griffiths, M.D.; Gjoneska, B.; Billieux, J.; Brand, M.; et al. Preventing Problematic Internet Use during the COVID-19 Pandemic: Consensus Guidance. Compr. Psychiatry 2020, 100, 152180. [CrossRef] [PubMed]

4. Cuan-Baltazar, J.Y.; Muñoz-Perez, M.J.; Robledo-Vega, C.; Pérez-Zepeda, M.F.; Soto-Vega, E. Misinformation of COVID-19 on the Internet: Infodemiology Study. JMIR Public Health Surveill. 2020, 6, e18444. [CrossRef] [PubMed]

5. Effenberger, M.; Kronbichler, A.; Shin, J.I.; Mayer, G.; Tilg, H.; Perco, P. Association of the COVID-19 Pandemic with Internet Search Volumes: A Google TrendsTM Analysis. Int. J. Infect. Dis. 2020, 95, 192-197. [CrossRef] [PubMed]

6. Mian, A.; Khan, S. Coronavirus: The Spread of Misinformation. BMC Med. 2020, 18, 89. [CrossRef] [PubMed]

7. Palinkas, L.A.; Horwitz, S.M.; Green, C.A.; Wisdom, J.P.; Duan, N.; Hoagwood, K. Purposeful Sampling for Qualitative Data Collection and Analysis in Mixed Method Implementation Research. Adm. Policy Ment. Health 2015, 42, 533-544. [CrossRef] [PubMed]

8. Bastani, P.; Bahrami, M.A. COVID-19 Related Misinformation on Social Media: A Qualitative Study from Iran (Preprint). J. Med Internet Res. 2020. [CrossRef] [PubMed]

9. Chan, A.K.M.; Nickson, C.P.; Rudolph, J.W.; Lee, A.; Joynt, G.M. Social Media for Rapid Knowledge Dissemination: Early Experience from the COVID -19 Pandemic. Anaesthesia 2020, 75, 1579-1582. [CrossRef] [PubMed]

10. Mavragani, A. Tracking COVID-19 in Europe: Infodemiology Approach. JMIR Public Health Surveill. 2020, 6, e18941. [CrossRef]

11. Li, C.; Chen, L.J.; Chen, X.; Zhang, M.; Pang, C.P.; Chen, H. Retrospective Analysis of the Possibility of Predicting the COVID-19 Outbreak from Internet Searches and Social Media Data, China, 2020. Eurosurveillance 2020, 25, 2000199. [CrossRef]

12. Rosenberg, H.; Syed, S.; Rezaie, S. The Twitter Pandemic: The Critical Role of Twitter in the Dissemination of Medical Information and Misinformation during the COVID-19 Pandemic. Can. J. Emerg. Med. 2020, 22, 418-421. [CrossRef]

13. Strzelecki, A. The Second Worldwide Wave of Interest in Coronavirus since the COVID-19 Outbreaks in South Korea, Italy and Iran: A Google Trends Study. Brain Behav. Immun. 2020, 88, 950-951. [CrossRef]

14. U.S. Reddit Reach by Gender 2021. Available online: https://www.statista.com/statistics/261765/share-of-us-internet-userswho-use-reddit-by-gender/ (accessed on 27 June 2021).

15. U.S. Reddit Reach by Age Group 2021. Available online: https://www.statista.com/statistics/261766/share-of-us-internet-userswho-use-reddit-by-age-group/ (accessed on 27 June 2021).

16. U.S. Reddit Reach by Ethnicity 2019. Available online: https://www.statista.com/statistics/261770/share-of-us-internet-userswho-use-reddit-by-ethnicity/ (accessed on 27 June 2021).

17. U.S. Reddit Reach by Education 2019. Available online: https://www.statista.com/statistics/261776/share-of-us-internet-userswho-use-reddit-by-education-level/ (accessed on 27 June 2021).

18. Reddit Users: Unique Monthly Visits 2019. Available online: https://www.statista.com/statistics/443332/reddit-monthlyvisitors / (accessed on 27 June 2021). 
19. Reddit: Traffic by Country. Available online: https://www.statista.com/statistics/325144/ reddit-global-active-user-distribution/ (accessed on 27 June 2021).

20. Most used Social Media 2021. Available online: https://www.statista.com/statistics/272014/global-social-networks-ranked-bynumber-of-users / (accessed on 27 June 2021).

21. Primack, B.A.; Shensa, A.; Sidani, J.E.; Whaite, E.O.; Lin, L.Y.; Rosen, D.; Colditz, J.B.; Radovic, A.; Miller, E. Social Media Use and Perceived Social Isolation Among Young Adults in the U.S. Am. J. Prev. Med. 2017, 53, 1-8. [CrossRef]

22. Sowles, S.J.; McLeary, M.; Optican, A.; Cahn, E.; Krauss, M.J.; Fitzsimmons-Craft, E.E.; Wilfley, D.E.; Cavazos-Rehg, P.A. A Content Analysis of an Online Pro-Eating Disorder Community on Reddit. Body Image 2018, 24, 137-144. [CrossRef]

23. Aladağ, A.E.; Muderrisoglu, S.; Akbas, N.B.; Zahmacioglu, O.; Bingol, H.O. Detecting Suicidal Ideation on Forums: Proof-ofConcept Study. J. Med. Internet Res. 2018, 20, e215. [CrossRef]

24. Rezaii, N.; Walker, E.; Wolff, P. A Machine Learning Approach to Predicting Psychosis Using Semantic Density and Latent Content Analysis. NPJ Schizophr. 2019, 5, 9. [CrossRef]

25. Bohrer, B.K.; Foye, U.; Jewell, T. Recovery as a Process: Exploring Definitions of Recovery in the Context of Eating-disorder-related Social Media Forums. Int. J. Eat. Disord. 2020, 53, 1219-1223. [CrossRef]

26. Nathan, N.A.; Nathan, K.I. Suicide, Stigma, and Utilizing Social Media Platforms to Gauge Public Perceptions. Front. Psychiatry 2020, 10, 947. [CrossRef]

27. Strand, M.; Gustafsson, S.A. Mukbang and Disordered Eating: A Netnographic Analysis of Online Eating Broadcasts. Cult. Med. Psychiatry 2020, 44, 586-609. [CrossRef]

28. Lavis, A.; Winter, R. Online Harms or Benefits? An Ethnographic Analysis of the Positives and Negatives of Peer-support around Self-harm on Social Media. J. Child Psychol. Psychiatr. 2020, 61, 842-854. [CrossRef]

29. Sowles, S.J.; Krauss, M.J.; Gebremedhn, L.; Cavazos-Rehg, P.A. I Feel like I've Hit the Bottom and Have No Idea What to Do: Supportive Social Networking on Reddit for Individuals with a Desire to Quit Cannabis Use. Subst. Abus. 2017, 38, 477-482. [CrossRef]

30. D'Agostino, A.R.; Optican, A.R.; Sowles, S.J.; Krauss, M.J.; Escobar Lee, K.; Cavazos-Rehg, P.A. Social Networking Online to Recover from Opioid Use Disorder: A Study of Community Interactions. Drug Alcohol Depend. 2017, 181, 5-10. [CrossRef]

31. Meacham, M.C.; Paul, M.J.; Ramo, D.E. Understanding Emerging Forms of Cannabis Use through an Online Cannabis Community: An Analysis of Relative Post Volume and Subjective Highness Ratings. Drug Alcohol Depend. 2018, 188, 364-369. [CrossRef]

32. Meacham, M.C.; Roh, S.; Chang, J.S.; Ramo, D.E. Frequently Asked Questions about Dabbing Concentrates in Online Cannabis Community Discussion Forums. Int. J. Drug Policy 2019, 74, 11-17. [CrossRef]

33. Cavazos-Rehg, P.; Grucza, R.; Krauss, M.J.; Smarsh, A.; Anako, N.; Kasson, E.; Kaiser, N.; Sansone, S.; Winograd, R.; Bierut, L.J. Utilizing Social Media to Explore Overdose and HIV/HCV Risk Behaviors among Current Opioid Misusers. Drug Alcohol Depend. 2019, 205, 107690. [CrossRef]

34. Rosenbaum, D.; Weissman, C.; Anderson, T.; Petranker, R.; Dinh-Williams, L.-A.; Hui, K.; Hapke, E. Microdosing Psychedelics: Demographics, Practices, and Psychiatric Comorbidities. J. Psychopharmacol. 2020, 34, 612-622. [CrossRef]

35. Loi, B.; Zloh, M.; de Luca, M.A.; Pintori, N.; Corkery, J.; Schifano, F. 4,4'-Dimethylaminorex (“4,4'-DMAR"; “Serotoni”) Misuse: A Web-Based Study. Hum. Psychopharmacol. Clin. Exp. 2017, 32, e2575. [CrossRef]

36. Keller, M.S.; Mosadeghi, S.; Cohen, E.R.; Kwan, J.; Spiegel, B.M.R. Reproductive Health and Medication Concerns for Patients With Inflammatory Bowel Disease: Thematic and Quantitative Analysis Using Social Listening. J. Med. Internet Res. 2018, 20, e206. [CrossRef]

37. Wolffsohn, J.S.; Leteneux-Pantais, C.; Chiva-Razavi, S.; Bentley, S.; Johnson, C.; Findley, A.; Tolley, C.; Arbuckle, R.; Kommineni, J.; Tyagi, N. Social Media Listening to Understand the Lived Experience of Presbyopia: Systematic Search and Content Analysis Study. J. Med. Internet Res. 2020, 22, e18306. [CrossRef]

38. Kozinets, R.V. The International Encyclopedia of Digital Communication and Society. In International Encyclopedia of Digital Communication and Society; Mansell, R., Ed.; Sage: London, UK, 2015; Volume 12, pp. 1-8. [CrossRef]

39. Dyke, S. Utilising a Blended Ethnographic Approach to Explore the Online and Offline Lives of Pro-Ana Community Members. Ethnogr. Educ. 2013, 8, 146-161. [CrossRef]

40. Tenderich, A.; Tenderich, B.; Barton, T.; Richards, S.E. What Are PWDs (People With Diabetes) Doing Online? A Netnographic Analysis. J. Diabetes Sci. Technol. 2019, 13, 187-197. [CrossRef] [PubMed]

41. Schifano, F. Analyzing the Open/Deep Web to Better Understand the New/Novel Psychoactive Substances (NPS) Scenarios: Suggestions from CASSANDRA and NPS.Finder Research Projects. Brain Sci. 2020, 10, 146. [CrossRef] [PubMed]

42. Arillotta, D.; Schifano, F.; Napoletano, F.; Zangani, C.; Gilgar, L.; Guirguis, A.; Corkery, J.M.; Aguglia, E.; Vento, A. Novel Opioids: Systematic Web Crawling Within the e-Psychonauts' Scenario. Front. Neurosci. 2020, 14, 149. [CrossRef] [PubMed]

43. Catalani, V.; Arillotta, D.; Corkery, J.M.; Guirguis, A.; Vento, A.; Schifano, F. Identifying New/Emerging Psychoactive Substances at the Time of COVID-19; A Web-Based Approach. Front. Psychiatry 2021, 11, 632405. [CrossRef]

44. Catalani, V.; Corkery, J.M.; Guirguis, A.; Napoletano, F.; Arillotta, D.; Zangani, C.; Vento, A.; Schifano, F. Psychonauts' Psychedelics: A Systematic, Multilingual, Web-Crawling Exercise. Eur. Neuropsychopharmacol. 2021, 49, 69-92. [CrossRef]

45. Davey, Z.; Schifano, F.; Corazza, O.; Deluca, P.; on behalf of the Psychonaut Web Mapping Group. E-Psychonauts: Conducting Research in Online Drug Forum Communities. J. Ment. Health 2012, 21, 386-394. [CrossRef] 
46. Graddy, R.; Buresh, M.E.; Rastegar, D.A. New and Emerging Illicit Psychoactive Substances. Med. Clin. N. Am. 2018, 102, 697-714. [CrossRef]

47. Orsolini, L.; Papanti, G.D.; Francesconi, G.; Schifano, F. Mind Navigators of Chemicals' Experimenters? A Web-Based Description of E-Psychonauts. Cyberpsychol. Behav. Soc. Netw. 2015, 18, 296-300. [CrossRef]

48. Orsolini, L.; Francesconi, G.; Papanti, D.; Giorgetti, A.; Schifano, F. Profiling Online Recreational/Prescription Drugs' Customers and Overview of Drug Vending Virtual Marketplaces: Profiling the Online Drugs' Consumers. Hum. Psychopharmacol. Clin. Exp. 2015, 30, 302-318. [CrossRef]

49. Rinaldi, R.; Bersani, G.; Marinelli, E.; Zaami, S. The Rise of New Psychoactive Substances and Psychiatric Implications: A Wide-ranging, Multifaceted Challenge That Needs Far-reaching Common Legislative Strategies. Hum. Psychopharmacol. Clin. Exp. 2020, 35, e2727. [CrossRef]

50. Schifano, F.; Napoletano, F.; Chiappini, S.; Guirguis, A.; Corkery, J.M.; Bonaccorso, S.; Ricciardi, A.; Scherbaum, N.; Vento, A. New/Emerging Psychoactive Substances and Associated Psychopathological Consequences. Psychol. Med. 2021, 51, 30-42. [CrossRef]

51. COVID-19 Resources Page for People Who Use Drugs (PWUD) and Drug Service Providers in the Early Phase of the COVID-19 Pandemic. Available online: https:/ / www.emcdda.europa.eu/publications/ad-hoc/covid-19-resources_de (accessed on 27 June 2021).

52. The Implications of COVID-19 for People Who Use Drugs (PWUD) and Drug Service Providers. Available online: https: / / www.emcdda.europa.eu/publications / topic-overviews/covid-19-and-people-who-use-drugs_en (accessed on 27 June 2021).

53. European Monitoring Centre for Drugs and Drug Addiction. EMCDDA Operating Guidelines for the European Union Early Warning System on New Psychoactive Substances; Publications Office: Luxembourg, 2019.

54. Chiappini, S.; Schifano, F. What about Pharming? Issues Regarding the Misuse of Prescription and Over-the-Counter Drugs. Brain Sci. 2020, 10, 736. [CrossRef]

55. Lima, C.K.T.; de Carvalho, P.M.M.; de Lima, I.A.A.S.; de Nunes, J.V.A.O.; Saraiva, J.S.; de Souza, R.I.; da Silva, C.G.L.; Neto, M.L.R. The Emotional Impact of Coronavirus 2019-NCoV (New Coronavirus Disease). Psychiatry Res. 2020, 287, 112915. [CrossRef]

56. Rajkumar, R.P. COVID-19 and Mental Health: A Review of the Existing Literature. Asian J. Psychiatry 2020, 52, 102066. [CrossRef]

57. Yao, H.; Chen, J.-H.; Xu, Y.-F. Patients with Mental Health Disorders in the COVID-19 Epidemic. Lancet Psychiatry 2020, 7, e21. [CrossRef]

58. Schoonenboom, J.; Johnson, R.B. How to Construct a Mixed Methods Research Design. Köln. Z. Soziol. 2017, 69, 107-131. [CrossRef]

59. Shorten, A.; Smith, J. Mixed Methods Research: Expanding the Evidence Base. Evid. Based. Nurs. 2017, 20, 74-75. [CrossRef]

60. Kaur, M. Application of Mixed Method Approach in Public Health Research. Indian J. Commun. Med. 2016, 41, 93. [CrossRef]

61. Kozinets, R.V. The Field behind the Screen: Using Netnography for Marketing Research in Online Communities. J. Mark. Res. 2002, 39, 61-72. [CrossRef]

62. Reddit. Available online: https:/ / www.reddit.com/ (accessed on 27 June 2021).

63. A Community of People Who Look Out for Each Other. Available online: https://www.reddit.com/r/Drugs / (accessed on 27 June 2021).

64. Opioids_RCs. Available online: https:/ / www.reddit.com/r/Opioid_RCs / (accessed on 27 June 2021).

65. COVID-19 Stack: Research and Discussion on Supplements and Medications Relating to COVID-19. Available online: https: / / www.reddit.com/r/covid19stack/ (accessed on 27 June 2021).

66. Subreddits-Drugs. Available online: https:/ / www.reddit.com/r/Drugs/wiki/subreddits (accessed on 27 June 2021).

67. Reddit.com: Api Documentation. Available online: https://www.reddit.com/dev/api/ (accessed on 27 June 2021).

68. Github Camas/Reddit-Search. Available online: https:/ / github.com/camas/reddit-search/ (accessed on 27 June 2021).

69. Moser, A.; Korstjens, I. Series: Practical Guidance to Qualitative Research. Part 3: Sampling, Data Collection and Analysis. Eur. J. Gen. Pract. 2018, 24, 9-18. [CrossRef]

70. Erlingsson, C.; Brysiewicz, P. A Hands-on Guide to Doing Content Analysis. Afr. J. Emerg. Med. 2017, 7, 93-99. [CrossRef]

71. Elo, S.; Kyngäs, H. The Qualitative Content Analysis Process. J. Adv. Nurs. 2008, 62, 107-115. [CrossRef]

72. Varpio, L.; Paradis, E.; Uijtdehaage, S.; Young, M. The Distinctions Between Theory, Theoretical Framework, and Conceptual Framework. Acad. Med. 2020, 95, 989-994. [CrossRef]

73. Kontis, V.; Bennett, J.E.; Rashid, T.; Parks, R.M.; Pearson-Stuttard, J.; Guillot, M.; Asaria, P.; Zhou, B.; Battaglini, M.; Corsetti, G.; et al. Author Correction: Magnitude, Demographics and Dynamics of the Effect of the First Wave of the COVID-19 Pandemic on All-Cause Mortality in 21 Industrialized Countries. Nat. Med. 2021, 27, 562. [CrossRef]

74. Coronavirus Disease (COVID-19)—Events as They Happen. Available online: https://www.who.int/emergencies/diseases / novel-coronavirus-2019/events-as-they-happen (accessed on 6 June 2021).

75. Schifano, F.; Orsolini, L.; Duccio Papanti, G.; Corkery, J.M. Novel Psychoactive Substances of Interest for Psychiatry. World Psychiatry 2015, 14, 15-26. [CrossRef]

76. Dumas, T.M.; Ellis, W.; Litt, D.M. What Does Adolescent Substance Use Look Like During the COVID-19 Pandemic? Examining Changes in Frequency, Social Contexts, and Pandemic-Related Predictors. J. Adolesc. Health 2020, 67, 354-361. [CrossRef]

77. Zaami, S.; Marinelli, E.; Varì, M.R. New Trends of Substance Abuse During COVID-19 Pandemic: An International Perspective. Front. Psychiatry 2020, 11, 700. [CrossRef] 
78. Alcohol, Tobacco \& Other Drugs in Australia, About. Available online: https://www.aihw.gov.au/reports/alcohol/alcoholtobacco-other-drugs-australia/contents / about (accessed on 27 June 2021).

79. COVID-19 and Drugs. Available online: https://www.emcdda.europa.eu/topics/covid-19_en (accessed on 6 June 2021).

80. COVID-19 is Changing the Route of Illicit Drug Flows, Says UNODC Report. Available online: //www.unodc.org/unodc/en/ frontpage/2020/May/covid-19-is-changing-the-route-of-illicit-drug-flows--says-unodc-report.html (accessed on 27 June 2021).

81. GDS COVID-19 Special Edition: Key Findings Report. Available online: https://www.globaldrugsurvey.com/gds-covid-19 -special-edition-key-findings-report/ (accessed on 27 June 2021).

82. Cameron, D.; Smith, G.A.; Daniulaityte, R.; Sheth, A.P.; Dave, D.; Chen, L.; Anand, G.; Carlson, R.; Watkins, K.Z.; Falck, R. PREDOSE: A Semantic Web Platform for Drug Abuse Epidemiology Using Social Media. J. Biomed. Inform. 2013, 46, 985-997. [CrossRef]

83. Glowacki, E.M.; Glowacki, J.B.; Wilcox, G.B. A Text-Mining Analysis of the Public's Reactions to the Opioid Crisis. Subst. Abus. 2018, 39, 129-133. [CrossRef]

84. Correia, R.B.; Wood, I.B.; Bollen, J.; Rocha, L.M. Mining Social Media Data for Biomedical Signals and Health-Related Behavior. Annu. Rev. Biomed. Data Sci. 2020, 3, 433-458. [CrossRef]

85. Lopreite, M.; Panzarasa, P.; Puliga, M.; Riccaboni, M. Early Warnings of COVID-19 Outbreaks across Europe from Social Media. Sci. Rep. 2021, 11, 2147. [CrossRef] [PubMed]

86. Schifano, F. Recent Changes in Drug Abuse Scenarios: The New/Novel Psychoactive Substances (NPS) Phenomenon. Brain Sci. 2018, 8, 221. [CrossRef] [PubMed]

87. Ahmed, A. Reddit Reveals its 2020's Top Posts, Trends, Users Numbers, and More. Available online: https://www. digitalinformationworld.com/2020/12/reddit-reveals-its-2020s-top-posts.html (accessed on 30 June 2021).

88. Tsao, S.-F.; Chen, H.; Tisseverasinghe, T.; Yang, Y.; Li, L.; Butt, Z.A. What Social Media Told Us in the Time of COVID-19: A Scoping Review. Lancet Digit. Health 2021, 3, e175-e194. [CrossRef]

89. Walters, S. COVID-19 and People Who Use Drugs-A Commentary. Health Behav. Policy Rev. 2020, 7, 489-497. [CrossRef]

90. Vaidyanathan, G. Scientists Criticize Use of Unproven COVID Drugs in India. Nature 2020, 587, 187-188. [CrossRef]

91. Debunking COVID-19 (Coronavirus) Myths. Available online: https://www.mayoclinic.org/diseases-conditions/coronavirus / in-depth/coronavirus-myths / art-20485720 (accessed on 27 June 2021).

92. Nordling, L. Unproven Herbal Remedy against COVID-19 Could Fuel Drug-Resistant Malaria, Scientists Warn. Available online: https:/ / www.sciencemag.org/news/2020/05/unproven-herbal-remedy-against-covid-19-could-fuel-drug-resistantmalaria-scientists (accessed on 27 June 2021).

93. Ren, J.; Zhang, A.-H.; Wang, X.-J. Traditional Chinese Medicine for COVID-19 Treatment. Pharmacol. Res. 2020, 155, 104743. [CrossRef]

94. Hartogsohn, I. Constructing Drug Effects: A History of Set and Setting. Drug Sci. Policy Law 2017, 3, 205032451668332. [CrossRef]

95. Khan, S.; Siddique, R.; Li, H.; Ali, A.; Shereen, M.A.; Bashir, N.; Xue, M. Impact of Coronavirus Outbreak on Psychological Health. J. Glob. Health 2020, 10, 010331. [CrossRef]

96. Pedrosa, A.L.; Bitencourt, L.; Fróes, A.C.F.; Cazumbá, M.L.B.; Campos, R.G.B.; de Brito, S.B.C.S.; Simões e Silva, A.C. Emotional, Behavioral, and Psychological Impact of the COVID-19 Pandemic. Front. Psychol. 2020, 11, 566212. [CrossRef]

97. Vindegaard, N.; Benros, M.E. COVID-19 Pandemic and Mental Health Consequences: Systematic Review of the Current Evidence. Brain Behav. Immun. 2020, 89, 531-542. [CrossRef]

98. Pfefferbaum, B.; North, C.S. Mental Health and the Covid-19 Pandemic. N. Engl. J. Med. 2020, 383, 510-512. [CrossRef]

99. Martinotti, G.; Santacroce, R.; Pettorruso, M.; Montemitro, C.; Spano, M.; Lorusso, M.; di Giannantonio, M.; Lerner, A. Hallucinogen Persisting Perception Disorder: Etiology, Clinical Features, and Therapeutic Perspectives. Brain Sci. $2018,8,47$. [CrossRef]

100. Parnes, J.E.; Kentopp, S.D.; Conner, B.T.; Rebecca, R.A. Who Takes the Trip? Personality and Hallucinogen Use among College Students and Adolescents. Drug Alcohol Depend. 2020, 217, 108263. [CrossRef]

101. European Monitoring Centre for Drugs and Drug Addiction; European Police Office. EU Drug Markets: Impact of COVID 19; Publications Office: Luxemburg, 2020.

102. Di Trana, A.; Carlier, J.; Berretta, P.; Zaami, S.; Ricci, G. Consequences of COVID-19 Lockdown on the Misuse and Marketing of Addictive Substances and New Psychoactive Substances. Front. Psychiatry 2020, 11, 584462. [CrossRef]

103. Shahsavari, S.; Holur, P.; Wang, T.; Tangherlini, T.R.; Roychowdhury, V. Conspiracy in the Time of Corona: Automatic Detection of Emerging COVID-19 Conspiracy Theories in Social Media and the News. J. Comput. Soc. Sci. 2020, 3, 279-317. [CrossRef]

104. Earnshaw, V.A.; Eaton, L.A.; Kalichman, S.C.; Brousseau, N.M.; Hill, E.C.; Fox, A.B. COVID-19 Conspiracy Beliefs, Health Behaviors, and Policy Support. Transl. Behav. Med. 2020, 10, 850-856. [CrossRef]

105. Index-Redditorsinrecovery. Available online: https:/ / www.reddit.com/r/redditorsinrecovery/wiki/index (accessed on 27 June 2021).

106. Responding to Polydrug Use. Available online: https://www.emcdda.europa.eu/best-practice/briefings/responding-polydruguse_en (accessed on 27 June 2021).

107. Zangani, C.; Schifano, F.; Napoletano, F.; Arillotta, D.; Gilgar, L.; Guirguis, A.; Corkery, J.M.; Gambini, O.; Vento, A. The E-Psychonauts' 'Spiced' World; Assessment of the Synthetic Cannabinoids' Information Available Online. Curr. Neuropharmacol. 2020, 18, 966-1051. [CrossRef] 
108. Schifano, F.; Chiappini, S.; Corkery, J.M.; Scherbaum, N.; Guirguis, A. The E-Psychonaut Drugs' Psychopharmacology. Curr. Opin. Pharmacol. 2021, 57, 165-174. [CrossRef]

109. The Lancet Infectious Diseases. The COVID-19 Infodemic. Lancet Infect. Dis. 2020, 20, 875. [CrossRef]

110. Reddy, E.K.; Battula, S.; Anwar, S.; Sajith, A.M. Drug Re-Purposing Approach and Potential Therapeutic Strategies to Treat COVID-19. Milford Reg. Med. Cent. 2021, 21, 704-723. [CrossRef]

111. Soussan, C.; Andersson, M.; Kjellgren, A. The Diverse Reasons for Using Novel Psychoactive Substances-A Qualitative Study of the Users' Own Perspectives. Int. J. Drug Policy 2018, 52, 71-78. [CrossRef] [PubMed]

112. Soussan, C.; Kjellgren, A. The Users of Novel Psychoactive Substances: Online Survey about Their Characteristics, Attitudes and Motivations. Int. J. Drug Policy 2016, 32, 77-84. [CrossRef] [PubMed]

113. EMCDDA Trendspotter Briefing: Impact of COVID-19 on Patterns of Drug Use and Drug-Related Harms in Europe. Available online: https: / / www.emcdda.europa.eu/publications/ad-hoc-publication/impact-covid-19-patterns-drug-use-and-harms_en (accessed on 27 June 2021).

114. Yan, L.; Gan, Y.; Ding, X.; Wu, J.; Duan, H. The Relationship between Perceived Stress and Emotional Distress during the COVID-19 Outbreak: Effects of Boredom Proneness and Coping Style. J. Anxiety Disord. 2021, 77, 102328. [CrossRef]

115. De Carvalho, L.F.; Pianowski, G.; Gonçalves, A.P. Personality Differences and COVID-19: Are Extroversion and Conscientiousness Personality Traits Associated with Engagement with Containment Measures? Trends Psychiatry Psychother. 2020, 42, 179-184. [CrossRef] [PubMed]

116. Di Maria, C.N.; Lee, B.; Fischer, R.; Eiger, G. Cognitive Bias in the COVID-19 Pandemic. Cureus 2020, 12, e9019. [CrossRef]

117. Nikčević, A.V.; Marino, C.; Kolubinski, D.C.; Leach, D.; Spada, M.M. Modelling the Contribution of the Big Five Personality Traits, Health Anxiety, and COVID-19 Psychological Distress to Generalised Anxiety and Depressive Symptoms during the COVID-19 Pandemic. J. Affect. Disord. 2021, 279, 578-584. [CrossRef] [PubMed]

118. Solano Gámez, A. Resiliencia y Covid 19. Rev. Colomb. Obstet. Ginecol. 2020, 71, 7-8. [CrossRef] [PubMed]

119. Oliveira, J.; Silva, L.; Vidor, M.V.; de Araújo, V.Z.; Bellolio, F. Flexibilization of Science, Cognitive Biases, and the COVID-19 Pandemic. Mayo Clin. Proc. 2020, 95, 1842-1844. [CrossRef]

120. Cloninger, C.R.; Przybeck, T.; Svrakic, D.; Wetzel, R.D. The Temperament and Character Inventory (TCI): A Guide to Its Development and Use; Center for Psychobiology of Personality, Washington University: St. Louis, MO, USA, 1994.

121. De Raad, B. The Big Five Personality Factors: The Psycholexical Approach to Personality. APA PsycNet. Available online: https: / / psycnet.apa.org/record/2001-17509-000 (accessed on 27 June 2021).

122. Dughiero, G.; Schifano, F.; Forza, G. Personality Dimensions and Psychopathological Profiles of Ecstasy Users. Hum. Psychopharmacol. Clin. Exp. 2001, 16, 635-639. [CrossRef]

123. Miller, L. Predicting Relapse and Recovery in Alcoholism and Addiction: Neuropsychology, Personality, and Cognitive Style. J. Subst. Abus. Treat. 1991, 8, 277-291. [CrossRef]

124. Miller, L. Neuropsychodynamics of Alcoholism and Addiction: Personality, Psychopathology, and Cognitive Style. J. Subst. Abus. Treat. 1990, 7, 31-49. [CrossRef]

125. Howard, M.O.; Kivlahan, D.; Walker, R.D. Cloninger's Tridimensional Theory of Personality and Psychopathology: Applications to Substance Use Disorders. J. Stud. Alcohol 1997, 58, 48-66. [CrossRef]

126. Gerra, G.; Bertacca, S.; Zaimovic, A.; Pirani, M.; Branchi, B.; Ferri, M. Relationship of Personality Traits and Drug of Choice by Cocaine Addicts and Heroin Addicts. Subst. Use Misuse 2008, 43, 317-330. [CrossRef]

127. Miguel, F.K.; Machado, G.M.; Pianowski, G.; Carvalho, L. de F. Compliance with Containment Measures to the COVID-19 Pandemic over Time: Do Antisocial Traits Matter? Personal. Individ. Differ. 2021, 168, 110346. [CrossRef]

128. Lee, S.A.; Crunk, E.A. Fear and Psychopathology During the COVID-19 Crisis: Neuroticism, Hypochondriasis, ReassuranceSeeking, and Coronaphobia as Fear Factors. Omega 2020. [CrossRef]

129. Kroencke, L.; Geukes, K.; Utesch, T.; Kuper, N.; Back, M.D. Neuroticism and Emotional Risk during the COVID-19 Pandemic. J. Res. Personal. 2020, 89, 104038. [CrossRef]

130. Khosravi, M. Neuroticism as a Marker of Vulnerability to COVID-19 Infection. Psychiatry Investig. 2020, 17, 710-711. [CrossRef]

131. Pradhan, M.; Chettri, A.; Maheshwari, S. Fear of Death in the Shadow of COVID-19: The Mediating Role of Perceived Stress in the Relationship between Neuroticism and Death Anxiety. Death Stud. 2020, 1-5. [CrossRef]

132. Caci, B.; Miceli, S.; Scrima, F.; Cardaci, M. Neuroticism and Fear of COVID-19. The Interplay Between Boredom, Fantasy Engagement, and Perceived Control Over Time. Front. Psychol. 2020, 11, 574393. [CrossRef]

133. Schindler, A. Attachment and Substance Use Disorders-Theoretical Models, Empirical Evidence, and Implications for Treatment. Front. Psychiatry 2019, 10, 727. [CrossRef]

134. Monzani, D.; Gorini, A.; Mazzoni, D.; Pravettoni, G. Brief Report—Every Little Thing Gonna Be All Right (at Least for Me): Dispositional Optimists Display Higher Optimistic Bias for Infection during the Italian COVID-19 Outbreak. Personal. Individ. Differ. 2021, 168, 110388. [CrossRef] [PubMed]

135. Aspers, P. Empirical Phenomenology: A Qualitative Research Approach (The Cologne Seminars). Indo Pac. J. Phenomenol. 2009, 9 , 1-12. [CrossRef]

136. Chun Tie, Y.; Birks, M.; Francis, K. Grounded Theory Research: A Design Framework for Novice Researchers. SAGE Open Med. 2019, 7. [CrossRef] [PubMed] 
137. Du, C.; Lee, W.; Amin, K.A.; Lucioni, A.; Kobashi, K.C.; Lee, U.J. Beyond the Bump-Insight Into the Postpartum Women's Experience of Pelvic Organ Prolapse as Expressed on Reddit. Urology 2021, 150, 99-102. [CrossRef] [PubMed]

138. Sarker, A.; de Roos, A.; Perrone, J. Mining Social Media for Prescription Medication Abuse Monitoring: A Review and Proposal for a Data-Centric Framework. J. Am. Med. Inform. Assoc. 2020, 27, 315-329. [CrossRef] [PubMed]

139. Trifan, A.; Semeraro, D.; Drake, J.; Bukowski, R.; Oliveira, J.L. Social Media Mining for Postpartum Depression Prediction. Stud. Health Technol. Inform. 2020, 270, 1391-1392. [CrossRef]

140. Park, A.; Conway, M.; Chen, A.T. Examining Thematic Similarity, Difference, and Membership in Three Online Mental Health Communities from Reddit: A Text Mining and Visualization Approach. Comput. Hum. Behav. 2018, 78, 98-112. [CrossRef]

141. Orsolini, L.; Corkery, J.M.; Chiappini, S.; Guirguis, A.; Vento, A.; de Berardis, D.; Papanti, D.; Schifano, F. ‘New/Designer Benzodiazepines': An Analysis of the Literature and Psychonauts' Trip Reports. Curr. Neuropharmacol. 2020, 18, 809-837. [CrossRef]

142. Olteanu, A.; Castillo, C.; Diaz, F.; Kıcıman, E. Social Data: Biases, Methodological Pitfalls, and Ethical Boundaries. Front. Big Data 2019, 2, 13. [CrossRef]

143. Scherbaum, N.; Bonnet, U.; Hafermann, H.; Schifano, F.; Bender, S.; Grigoleit, T.; Kuhn, J.; Nyhuis, P.; Preuss, U.W.; Reymann, G.; et al. Availability of Illegal Drugs During the COVID-19 Pandemic in Western Germany. Front. Psychiatry 2021, $12,648273$. [CrossRef] 